\title{
Chinese Teaching and Humanistic Quality Training in Higher Vocational Colleges
}

\author{
Shuhong Sun \\ Changchun Vocational Institute of Technology, Changchun, China \\ sunshuhongcc@126.com
}

Keywords: higher vocational college; college Chinese; humanistic quality

\begin{abstract}
The general lack of humanistic education in higher vocational colleges has caused widespread concern from all walks of life, and it has become an urgent task for higher vocational colleges to strengthen students' humanistic quality. Humanism is the fundamental attribute of college Chinese, and humanistic education is the fundamental task and tenet of college Chinese education. In view of the status quo of college students' humanistic quality, this paper puts forward strategies to strengthen humanistic quality training in the teaching of College Chinese and contribute ideas to enhance the quality of contemporary college students in an all-round way.
\end{abstract}

\section{Introduction}

Humanistic quality refers to the humanistic knowledge possessed by people, as well as the integrated quality and development degree of spiritual outlook, moral cultivation and behavioral pattern, etc. internalized in this knowledge. Carrying out humanistic quality education on college students is conducive to improving their overall quality and facilitating them to become true talents. This is exactly the goal of higher education and also the requirement and hope of the country and society. A majority of students in higher vocational colleges feel frustrated in the general context of exam-oriented education. They have great mental stress, superficial non-professional knowledge and many courses to make up in terms of humanistic quality. Compared with general undergraduate colleges, higher vocational colleges should lay more emphasis on the training of students' humanistic quality. As a public fundamental course in higher vocational colleges, college Chinese has become an important path to implement humanistic quality education in higher vocational colleges.

\section{The Status Quo of College Students’ Humanistic Quality}

\subsection{The humanistic knowledge is insufficient and the cultural quality is yet to be improved}

Apart from learning step by step in the limited classroom time, college students seldom spend time in constructing cultural knowledge. The problems of truancy and looking for people to sign in, etc. are very common in college classroom and recur frequently. Therefore, in hard indicators, students don't have enough knowledge reserves ${ }^{[1]}$. Besides, students spend most of their time on entertainment and social activities. They are not very enthusiastic about all kinds of beneficial club activities, public welfare activities and exploration of excellent national culture. Although some college students have certain knowledge and technical level, their knowledge scope is one-sided and narrow. Their overall quality is yet to be improved. Especially, they must strengthen self-learning in humanistic quality.

\subsection{The value orientation is utilitarian and short-sighted and there is a lack of long-term life goal}

In recent years, influenced by utilitarianism and money worship, many college students lose lofty ideal and firm conviction. They lack an essential sense of responsibility and dedication to the country, nation and society and even suffer from spiritual loss and moral decline, etc. With respect 
to major selection, course learning and career goal, they no longer regard national needs and personal ideals as a compass and impetus, or have a strong enterprising spirit and tenacious faith. Instead, they consider wangling a diploma to earn a living, obtaining generous income or striving for an opportunity to go abroad as the main life goal. Quite a few students regard economic scale as the only coordinate that directs their individual behavior and put profits before everything ${ }^{[2]}$.

\subsection{The self-consciousness is too strong and the humanistic values are insufficient}

Traditional outlooks of good and evil, beauty and ugliness, as well as moral standards, are obviously absent among many college students. On the campus, numerous students have uncivil behaviors, a low taste of life, rude words and vulgar conducts. They lack basic etiquettes and self-discipline, have a superficial understanding of meaning of life and don't have the ability to distinguish good from evil, beauty from ugliness. Being self-centered, they focus on individual gains and losses, take much, give little and neglect their due responsibilities and obligations in the society. Also they have a weak willpower, can't endure setbacks, often have mood swings, easily get enthusiastic, excited and stimulated, or extremely discouraged, depressed and disappointed. They don't have self-counseling and self-regulation ability in psychology.

\section{Strategies to Strengthen Humanistic Quality Training in College Chinese Teaching}

\subsection{To establish the important status of college Chinese as a core course in humanistic quality education}

College Chinese is a public fundamental course in all colleges and universities. Similar to other public fundamental courses, it has a low status. Humanistic quality training, in particular, doesn't receive enough attention. As the importance of college Chinese education in humanistic quality training gradually sneaks in, many colleges consider college Chinese as a compulsory course. The academic status has gradually been improved. In the overall curriculum setting, college Chinese is treated as a comprehensive subject, whose covers history, ethics, politics, philosophy, society, education, military affairs and other knowledge in humanistic science and natural science. This just highlights the important role of college Chinese education in the training process of college students' humanistic quality ${ }^{[3]}$. College Chinese course should be raised to a more important status and learned as a compulsory course in colleges. The course positioning, textbook selection and teaching method must be reformed, to better satisfy the requirements of college students' humanistic quality training.

\subsection{To observe the law of college Chinese education and inspire students' humanistic quality}

By saying "observing the general law of college Chinese education”, we mean we must select some classic humanistic materials, based on the explanation of basic knowledge, inspire students emotionally and sublimate their ideology, in the teaching process of college Chinese. By guiding students to read classic Chinese materials with aesthetic taste and ideological enlightenment, we not only arouse the potential humanistic feelings of students, so that they can draw nutrients of humanistic spirit, but also improve their linguistic appreciation ability and literary aesthetic ability, so that their ability to use language can be significantly improved. The selection of college Chinese textbook must widely assimilate ancient, modern, Chinese and foreign classic literature works. In this way, teachers can not only broaden students' horizons and let them feel the different characteristics of Chinese and foreign cultures, but also help cultivate their excellent qualities of active exploration and aggressiveness.

\subsection{To innovate teaching methods of college Chinese to meet the demands of social development}

Preciously, Chinese teaching mainly centered on the explanation of textbook. Humanistic quality education was generally conduced in the form of extra-curricular reading activities and reading exchanges between teachers and students. A good humanistic quality method should train students' humanistic quality subtly and enhance their independent thinking ability, while letting 
them learn Chinese knowledge. In the teaching process, teachers may break away from the arrangement of textbooks, add some reading exchange activities on literary works with humanistic themes and analyze excellent humanistic qualities in literary works, from the angles of historical background, characters' personality, life experience and cultural accomplishment, etc. On the other hand, teachers can adopt dynamic learning, use students' learning performance at ordinary times, use of knowledge and collection of paper materials, etc. as a basis for final assessment, so as to improve their enthusiasm for learning humanistic quality ${ }^{[4]}$.

\subsection{To improve the quality of college Chinese teachers}

An excellent college Chinese teacher must strengthen the reserve of humanistic knowledge and possess an advanced humanistic concept, based on a certain charisma. Teachers need to exchange and communicate more with students and let them feel humanistic care. At the same time, they should take work seriously and treat students sincerely ${ }^{[5]}$. Knowledge reserve is the most important part of a teacher. Only when teachers have a certain knowledge reserve can they give humanistic education properly. Teachers should expand their knowledge scope and accumulate knowledge in teaching and self-learning constantly, transform knowledge into their own power, pass on such knowledge to students through their own words and deeds and improve the level of humanistic teaching, using their own noble humanistic quality.

\subsection{To expand and integrate the content in College Chinese}

As a carrier of knowledge, textbooks are loaded with rich contents, such as literature, aesthetics, expression, speculation and humanities, with a large room and flexibility. We must expand and integrate the content of textbooks. College Chinese textbooks are either selected from textbooks of famous colleges or developed by colleges independently, highlight instrumentality and humanistic education and concentrate the humanistic spirit to disseminate positive ethos in classics. In the meantime, Chinese teaching should be associated with regional characteristics and local culture, vary from person to person, from region to region, communicate students' rustic and country yearning properly, be cultural, humanistic, emotional and regional, shape temperament and soul virtually and contribute to the development and improvement of overall personality quality.

\subsection{To reform the evaluation model of College Chinese}

It is imperative to optimize course assessment. We may change final and summative assessment into process assessment and incorporate homework, class presentation, discussion and even extracurricular practice, etc. into assessment content; reform the examination model and combine open-book exam, closed-book exam, oral test with written test, etc.; pay attention to assessing students' ability to use Chinese knowledge and strive to make the assessment content and methods of College Chinese rich, diversified and flexible.

\section{Conclusions}

The development of college Chinese course should be practically combined with the cultivation of students' humanistic quality and enhance students' linguistic comprehension and analysis ability by training their listening, speaking, reading and writing skills, thus penetrating humanistic knowledge and humanistic connotations in college Chinese course into the depth of students' soul successfully. It is a long-term and systematic project to implement humanistic quality education in college Chinese teaching. On the one hand, the administrative department for education and school leadership shall attach importance and give support, to enable a good external environment for college Chinese teaching. On the other hand, college Chinese teachers shall treat "imparting knowledge and educating people" as their own duty, strive to improve their knowledge level and professional ability and continue to deepen teaching reforms and practice. Only in doing this can we put the effect of humanistic quality education into reality and truly realizethe teaching goal of college Chinese. 


\section{References}

[1] Hong Shan, Countermeasures for the Absence of Humanistic Quality Education in Vocational Colleges [J], Journal of Huangshan University, 2010,(2).

[2] Cheng Nensheng, On Humanistic Quality Education in College Chinese Teaching [J], China Adult Education, 2010(21).

[3] Yao Di, Strengthening the Humanistic Quality Education in College Chinese [J], Journal of Educational Institute of Jilin Province, 2011(7).

[4] Han Yu, Exploring the Path to Improve the Humanistic Quality of Vocational College Students in College Chinese Curriculum Reform[J], China After School Education, 2014 (11).

[5] Jiang Chengyong, College Chinese Teaching and College Students' Humanistic Quality Training[J],China University Teaching 2013 (02). 